\title{
METODE PIECES DALAM MENGUKUR TINGKAT KEPUASAN PENGGUNA PORTAL AKADEMIK
}

\author{
Dede Wira Trise Putra ${ }^{1)}$, Hasanul Bulkis ${ }^{2)}$, Putri Mandarani ${ }^{3)}$, Anna Syahrani ${ }^{4)}$ \\ ${ }^{1234}$ Fakultas Teknik, Institut Teknologi Padang \\ email: dedewtp339@yahoo.com
}

\begin{abstract}
Abstrak
Abstrak : Portal akademik merupakan sebuah cara dalam menyebarkan informasi yang cepat kepada para pengguna serta dapat membantu dalam penyelesaian masalah yang dimiliki oleh sebuah institusi. Sebuah portal akademik yang merupakan sebuah sistem informasi digunakan oleh pengguna yang beragam. Keberagaman ini akan membuat pengguna puas maupun tidak puas dengan sistem yang ada sehingga perlu pengembangan lebih lanjut kedepannya. Salah satu metode yang dapat digunakan dalam mengukur tingkat kepuasan pengguna adalah metode pieces yang memiliki variabel penilaian performance, information, economy, control, efficiency dan service. Penelitian menggunakan kuisioner pada responden pengguna aktif portal akademik yang dilakukan penyebarannya melalui platform google form. Kuisioner menghasilkan tingkat kepuasan yang diperoleh hasil cukup baik. Perbaikan untuk pengembangan ke depan difokuskan pada variabel kontrol yang memiliki nilai terendah 450,67. Berdasarkan hasil kuisioner variabel kontrol memiliki penilaian rendah terhadap kondisi akses akun pada portal akademik, sehingga diperlukan pengembangan terhadap tampilan notifikasi peringatan ketika akun digunakan lebih dari satu perangkat.
\end{abstract}

Kata kunci : Akademik, Kuisioner, Pieces, Control

Abstract :The academic portal is a way to quickly disseminate information to users and can assist in solving problems that are owned by an institution. An academic portal which is an information system used by various users. This diversity will make users satisfied or dissatisfied with the existing system so that further development is needed in the future. One method that can be used to measure the level of user satisfaction is the pieces method which has variables of performance, information, economy, control, efficiency and service assessment. The study used questionnaires on active users of academic portals which were distributed through the Google Form platform. Questionnaire produces a level of satisfaction obtained quite good results. Improvements for future development are focused on the control variable which has the lowest value of 450.67. Based on the results of the questionnaire, the control variable has a low assessment of the condition of account access on the academic portal, so it is necessary to develop a warning notification display when the account is used more than one device.

Keywords : Academic, Questionnaire, Pieces, Control

\section{PENDAHULUAN}

Portal akademik merupakan sebuah portal yang dibangun ke dalam sebuah sistem informasi yang dirancang dalam media website maupun mobile untuk memenuhi kebutuhan pelayanan terhadap pendidikan dalam peningkatan kinerja, kualitas, dan daya saing yang maksimal [Saputra, Arif]. Portal akademik dibangun berdasarkan kebutuhan dari pengguna langsung terhadap sistem sehingga dapat menyelesaikan masalah yang dihadapi
[Nuryanti, Yulis]. Portal akademik di institusi pendidikan merupakan sebuah langkah dalam membantu mahasiswa melakukan kegiatan tatap muka langsung dan update informasi yang dapat berjalan secara cepat. Sistem terkomputerisasi melalui portal akademik dapat membantu kinerja dan capaian sebuah institusi [Elmawati].

Portal akademik sebagai sebuah sistem yang dibangun berdasarkan kebutuhan dan memiliki pengguna yang beragam maka 
akan muncul sebuah kondisi dimana pengguna puas dan tidak puas terhadap sistem yang dibangun. Kepuasan maupun tidaknya pengguna dapat menjadi feedback bagi pengembang portal kedepannya. Portal akademik yang memiliki konteks sebagai sebuah sistem informasi yang dikemas dengan platform dengan tujuan mempermudah akses informasi bagi pengguna [Hamid, Abdul].

Sebuah portal akademik akan memiliki fase pengembangan dimana fase tersebut akan dimulai dari feedback dari pengguna. Pieces merupakan salah satu metode yang dapat digunakan dalam menilai apakah sebuah sistem sudah memiliki kesesuaian dengan tujuannya dibangun [Nuryanti, Yulis]. Metode pieces memiliki variabel yakni performance, information, economics, control, efficiency dan service [Agustina, Nani]. Variabel ini akan digunakan dalam mengukur tingkat kekuatan dan kelemahan yang dimiliki oleh sebuah portal [Indrawati].

Pengembangan portal akademik selama ini didasarkan pada kebutuhan terhadap proses yang berjalan pada instansi, namun belum dilakukan survey terhadap kepuasan pengguna pada fitur dan tampilan yang dimiliki. Hal ini membuat pengguna aktif yang umumnya berasal dari kalangan mahasiswa mengalami kendala terutama pada pengguna aktif yang masih baru. Pengembangan fitur pada portal masih belum berdasarkan kebutuhan pengguna. Hal ini membuat pengguna mengalami kendala dalam memahami fitur yang ada. Sehingga diperlukan penelitian dengan melakukan survey untuk mengukur tingkat kepuasan pengguna terhadap portal akademik. Metode yang digunakan dapat membantu mengkur masalah yang dibahas sebelumnya, sehingga dapat dilakukan pengembangan fitur dan tampilan sesuai kebutuhan pengguna.

\section{METODE PENELITIAN}

Metode penelitian yang digunakan adalah eksperimen dengan merubah secara sistematis satu atau lebih variabel, serta metode survei untuk mendapatkan data dari responden [Sari, Yolanda Rizkyta]. Responden yang diambil sebanyak 136 orang dengan latar belakang pengguna aktif portal akademik.

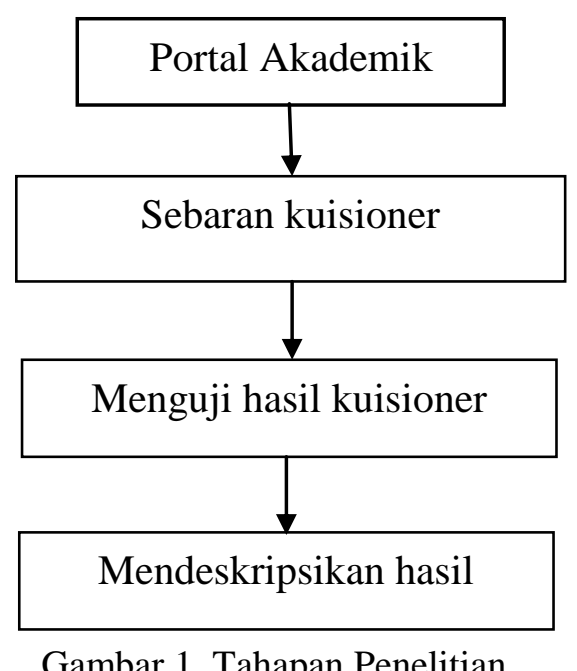

Gambar 1 di atas merupakan tahapan penelitian yang dimulai dari portal akademik sebagai studi kasus sampai pada tahap deskripsi hasil penelitian.

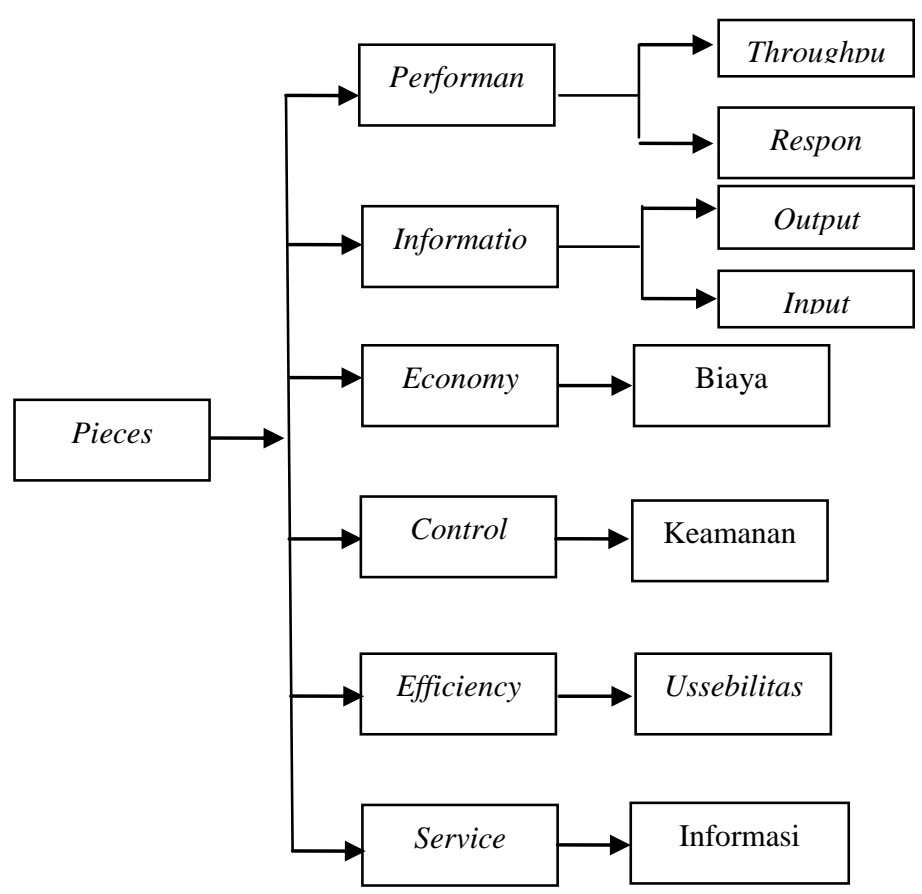

Gambar 2. Metode Pieces 
Gambar 2 merupakan rincian metode berdasarkan variabel yang akan digunakan dalam kuisoner [Safarudin, Muhamad Sigid]. Tabel 1 merupakan daftar pernyataan yang akan digunakan dalam kuisioner berdasarkan variabel pada metode pieces.

Tabel 1. Daftar Pernyataan Penelitian

\begin{tabular}{cl}
\hline No & \multicolumn{1}{c}{ Pernyataan } \\
\hline PERFORMANCE (Kinerja) \\
\hline 1 & $\begin{array}{l}\text { Pilihan menu yang tersedia pada website } \\
\text { sisfo ITP dapat memudahkan pengguna }\end{array}$ \\
2 & $\begin{array}{l}\text { Penyusunan tata letak tampilan menu } \\
3\end{array}$ \\
\hline Waktu tunggu pada setiap menu yang \\
dibuka
\end{tabular}

Skala likert yang digunakan pada penelitian ini yakni digolongkan pada baik, cukup baik dan tidak baik. Hasil dari penggunaan skala likert akan merubah bentuk jawaban sehingga data dapat digunakan [Saputra, Arif].
Data yang digunakan pada penelitian ini berasal dari penyebaran kuesioner terhadap pengguna aktif portal akademik. Kuesioner dirancang menggunakan bantuan google form dan disebarkan melalui media sosial dengan keharusan mengisi program studi dan nomor induk mahasiswa untuk proses validasi pengguna. Total responden ynag mengisi kuisioner ini sebanyak 110 responden yang berasal dari berbagai program studi dan merupakan pengguna aktif portal akademik. Pernyataan yang digunakan pada kuisioner seperti terlihat pada tabel 1 yang terdiri atas 20 pernyataan dan menggunakan 6 indikator pernyataan dengan rinician Performance dengan 3 indikator pernyataan, Information dengan 6 indikator pernyataan, Economy 2 indikator pernyataan, Control dengan 3 indikator pernyataan, Efficiency dengan 2 indikator pernyataan, dan Service dengan 4 indikator pernyataan.

Pengujian terhadap data responden dilakukan dengan beberapa uji antara lain [Zahra, R Ratika]:

a. Uji validitas digunakan untuk mengukur sah atau tidaknya suatu kuesioner.

b. Uji reliabilitas digunakan untuk mengetahui konsistensi alat ukur, apakah alat pengukur yang digunakan dapat diandalkan dan tetap konsisten jika pengukuran tersebut diulang.

c. Uji normalitas adalah sebuah uji yang bertujuan untuk menilai sebaran pada sebuah kelompok data atau variabel, untuk melihat data tersebut berdistribusi normal atau tidak berdasarkan pada variabel pengganggu [Jamaludin].

\section{HASIL DAN PEMBAHASAN}

Pengolahan data terhadap kuisioner yang diberikan pada responden setelah melewati beberapa proses ujia mendapatkan hasil pada uji validitas variabel yakni semua data dari hasil 
responden memenuhi nilai signifikan $\leq$ 0,05 maka semua data valid.

Berdasarkan uji reliabilitas yang dilakukan terhadap semua data valid dari hasil uji validitas maka diperoleh hasil 0,899 yang berarti nilai konsistensi alat ukur baik.

Uji normalitas yang dilakukan untuk setiap variabel yang digunakan mendapatkan hasil sebagai berikut :

a. Hasil uji normalitas untuk variabel performance

Tabel 2. Uji Normalitas Performance

\begin{tabular}{|c|c|c|}
\hline \multicolumn{3}{|c|}{ Statistics } \\
\hline perfo & & \\
\hline \multirow{2}{*}{$\mathrm{N}$} & Valid & 408 \\
\hline & Missing & 408 \\
\hline \multicolumn{2}{|c|}{ Mean } & 3.51 \\
\hline \multicolumn{2}{|c|}{ Median } & 3.00 \\
\hline \multicolumn{2}{|c|}{ Mode } & 3 \\
\hline \multicolumn{2}{|c|}{ Skewness } & .567 \\
\hline \multicolumn{2}{|c|}{ Std. Error of Skewness } & .121 \\
\hline \multicolumn{2}{|c|}{ Kurtosis } & -.421 \\
\hline \multicolumn{2}{|c|}{ Std. Error of Kurtosis } & .241 \\
\hline
\end{tabular}

Tabel 2 digunakan untuk mengetahui data normal atau tidak dengan perhitungan sebagai berikut :

$$
\text { Zskewness }=\frac{S-o}{\text { SEskewness }}
$$

$$
(0,121 / 0,567=0,213)
$$$$
\text { Zkurtosis }=\frac{K-o}{\text { SEkurtosis }}
$$

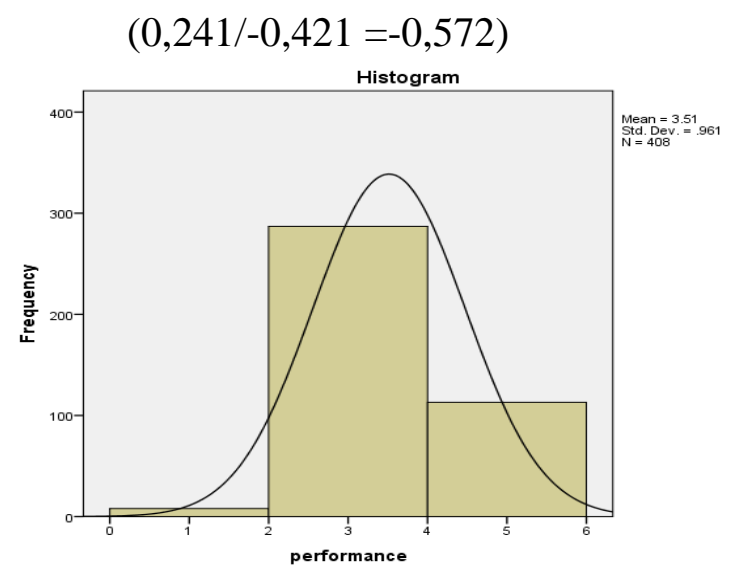

Gambar 3. Grafik Histogram Performance
Gambar 3 merupakan grafik histogram variabel performance dengan rata-rata adalah 3,51. Berdasarkan perhitungan pada hasil Zakewness dengan skor -0,419 dan Zkurtosis 0,239 yang berarti variabel performance memiliki data normal.

b. Hasil uji normalitas untuk variabel information

Tabel 3 Uji Normalitas Information

\section{Statistics}

\begin{tabular}{|c|c|c|}
\hline \multirow{2}{*}{$\mathrm{N}$} & Valid & 816 \\
\hline & Missing & 0 \\
\hline \multicolumn{2}{|c|}{ Mean } & 3.37 \\
\hline \multicolumn{2}{|c|}{ Median } & 3.00 \\
\hline \multicolumn{2}{|c|}{ Mode } & 3 \\
\hline \multicolumn{2}{|c|}{ Skewness } & -.205 \\
\hline \multicolumn{2}{|c|}{ Std. Error of Skewness } & .086 \\
\hline \multicolumn{2}{|c|}{ Kurtosis } & -.714 \\
\hline \multicolumn{2}{|c|}{ Std. Error of Kurtosis } & .171 \\
\hline
\end{tabular}

information

Tabel 3 digunakan untuk menghitung normal atau tidaknya data dengan menggunakan formula (1) dan formula (2) yang menghasilkan

$$
\begin{aligned}
& (0,086 /-0,205=-0,419) \\
& (0,171 /-0,714=-0,239)
\end{aligned}
$$

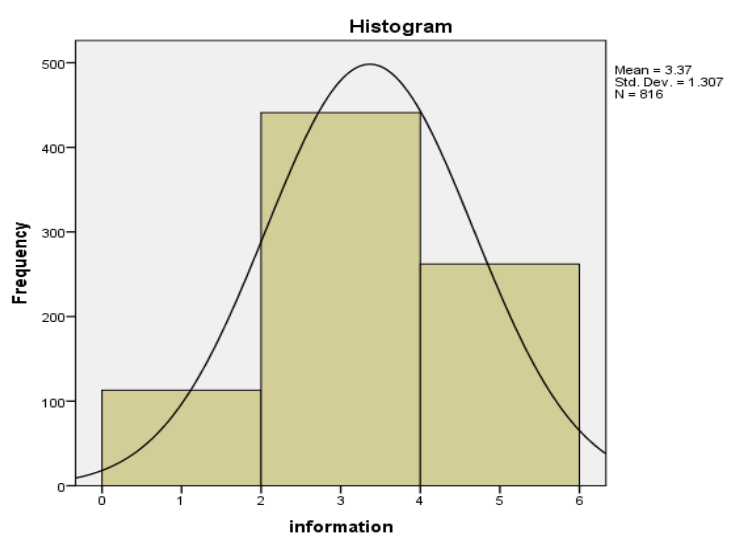

Gambar 4. Grafik Histogram Information

Gambar 4 merupakan grafik histogram variabel information dengan rata-rata adalah 3,37. Berdasarkan perhitungan pada hasil Zakewness 
memiliki skor -0,2387 dan Zkurtosis 0,821 dengan hasil variabel information memiliki data normal.

c. Hasil uji normalitas untuk variabel economy

Tabel 4. Uji Normalitas Economy

Statistics

\begin{tabular}{|c|c|c|}
\hline \multicolumn{3}{|c|}{ Economy } \\
\hline \multirow{2}{*}{$\mathrm{N}$} & Valid & 272 \\
\hline & Missing & 544 \\
\hline \multicolumn{2}{|c|}{ Mean } & 3.43 \\
\hline \multicolumn{2}{|c|}{ Median } & 3.00 \\
\hline \multicolumn{2}{|c|}{ Mode } & 3 \\
\hline \multicolumn{2}{|c|}{ Skewness } & -.062 \\
\hline \multicolumn{2}{|c|}{ Std. Error of Skewness } & .148 \\
\hline \multicolumn{2}{|c|}{ Kurtosis } & -.354 \\
\hline \multicolumn{2}{|c|}{ Std. Error of Kurtosis } & .294 \\
\hline
\end{tabular}

Tabel 4 untuk mengetahui data normal atau tidak dapat dilakukan dengan menggunakan formula (1) dan (2) sebagai berikut :

$$
\begin{aligned}
(0,148 /-0,062 & =-2,387) \\
(0,294 /-0,354 & =-0,821)
\end{aligned}
$$

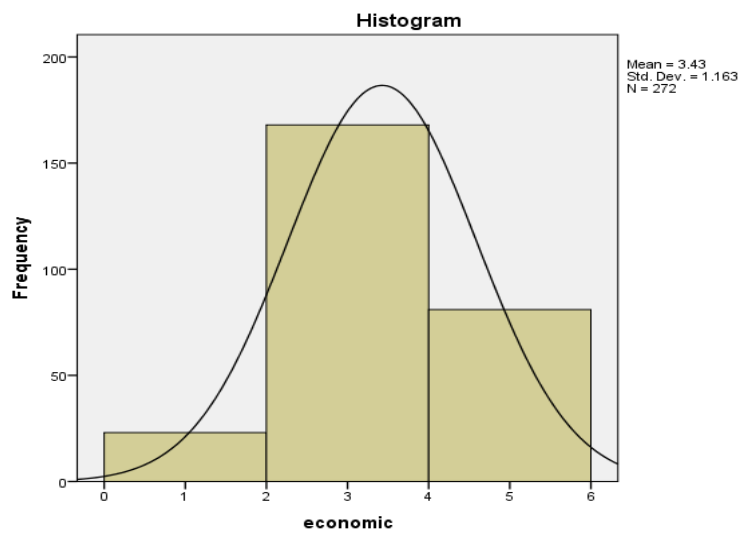

Gambar 5. Grafik Histogram Economy

Gambar 5 merupakan grafik histogram variabel economy dengan rata-rata adalah 3,43. Berdasarkan perhitungan pada hasil Zakewness 0,812 dan Zkurtosis -0,397 yang berarti variabel economy memiliki data normal. d. Hasil uji normalitas untuk variabel control

\begin{tabular}{|c|c|c|}
\hline \multicolumn{3}{|c|}{ Statistics } \\
\hline contr & & \\
\hline \multirow{2}{*}{$\mathrm{N}$} & Valid & 408 \\
\hline & Missing & 408 \\
\hline \multicolumn{2}{|c|}{ Mean } & 3.31 \\
\hline \multicolumn{2}{|c|}{ Median } & 3.00 \\
\hline \multicolumn{2}{|c|}{ Mode } & 3 \\
\hline \multicolumn{2}{|c|}{ Skewness } & -.149 \\
\hline \multicolumn{2}{|c|}{ Std. Error of Skewness } & .121 \\
\hline \multicolumn{2}{|c|}{ Kurtosis } & -.607 \\
\hline \multicolumn{2}{|c|}{ Std. Error of Kurtosis } & .241 \\
\hline
\end{tabular}

Tabel 5. Uji Normalitas Control

Tabel 5 digunakan untuk mengetahui data normal atau tidak dapat dilakukan dengan menggunakan formula (1) dan (2) sebagai berikut :

$$
\begin{aligned}
& (0,121 /-0,149=-0,812) \\
& (0,241 /-0,607=-0,397)
\end{aligned}
$$

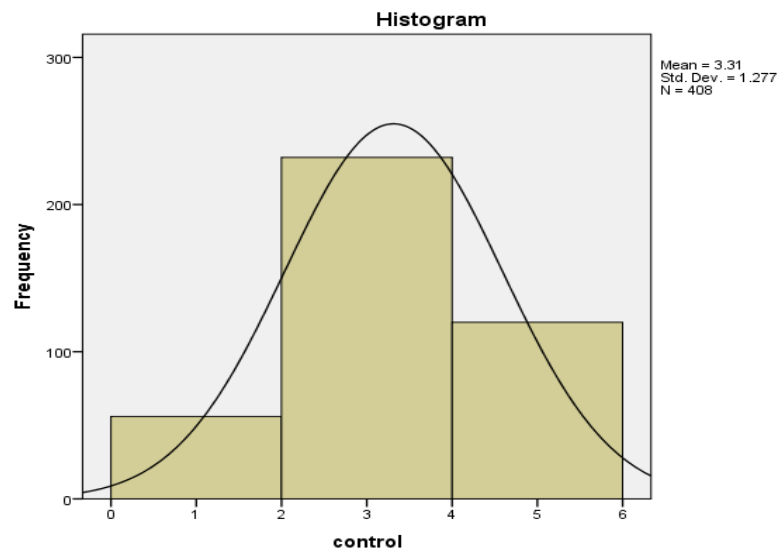

Gambar 7. Grafik Histogram Efficiency

Gambar 7 merupakan grafik histogram variabel efficiency dengan rata-rata adalah 3,31. Berdasarkan perhitungan pada hasil Zakewness dengan skor -0,89 dan Zkurtosis -0,53 yang berarti variabel control memiliki data normal. 
e. Hasil uji normalitas untuk variabel efficiency

Tabel 6. Uji Normalitas Efficiency

Statistics

\begin{tabular}{|c|c|c|}
\hline \multirow{2}{*}{$\mathrm{N}$} & Valid & 272 \\
\hline & Missing & 544 \\
\hline \multicolumn{2}{|c|}{ Mean } & 3.40 \\
\hline \multicolumn{2}{|c|}{ Median } & 3.00 \\
\hline \multicolumn{2}{|c|}{ Mode } & 3 \\
\hline \multicolumn{2}{|c|}{ Skewness } & -.166 \\
\hline \multicolumn{2}{|c|}{ Std. Error of Skewness } & .148 \\
\hline \multicolumn{2}{|c|}{ Kurtosis } & -.552 \\
\hline \multicolumn{2}{|c|}{ Std. Error of Kurtosis } & .294 \\
\hline
\end{tabular}

Tabel 6 untuk mengetahui data normal atau tidak dapat dilakukan dengan menggunakan formula (1) dan (2) sebagai berikut :

$$
\begin{aligned}
& (0,148 /-0,166=-0,89) \\
& (0,294 /-0,552=-0,53)
\end{aligned}
$$

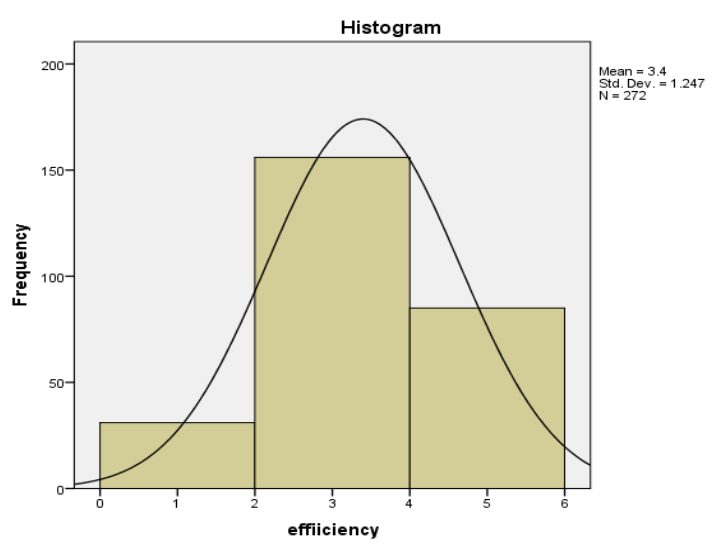

Gambar 8. Grafik Histogram Control

Gambar 8 merupakan grafik histogram variabel control dengan ratarata adalah 3,40. Berdasarkan perhitungan pada hasil Zakewness dengan skor -0,37 dan Zkurtosis -0,29 yang berarti variabel efficiency memiliki data normal. f. Hasil uji normalitas untuk variabel service

Tabel 7. Uji Normalitas Service

\begin{tabular}{|c|c|c|}
\hline \multirow{2}{*}{ N } & Valid & 544 \\
\hline & Missing & 272 \\
\hline \multicolumn{2}{|c|}{ Mean } & 3.48 \\
\hline \multicolumn{2}{|c|}{ Median } & 3.00 \\
\hline \multicolumn{2}{|c|}{ Mode } & 3 \\
\hline \multicolumn{2}{|c|}{ Skewness } & -.279 \\
\hline \multicolumn{2}{|c|}{ Std. Error of Skewness } & .105 \\
\hline \multicolumn{2}{|c|}{ Kurtosis } & -.709 \\
\hline \multicolumn{2}{|c|}{ Std. Error of Kurtosis } & .209 \\
\hline
\end{tabular}

\section{Statistics}

Tabel 7 untuk mengetahui data normal atau tidak dapat dilakukan dengan menggunakan rumus sebagai berikut :

$$
\begin{aligned}
& (0,105 /-0,279=-0,37) \\
& (0,209 /-0,709=-0,29)
\end{aligned}
$$

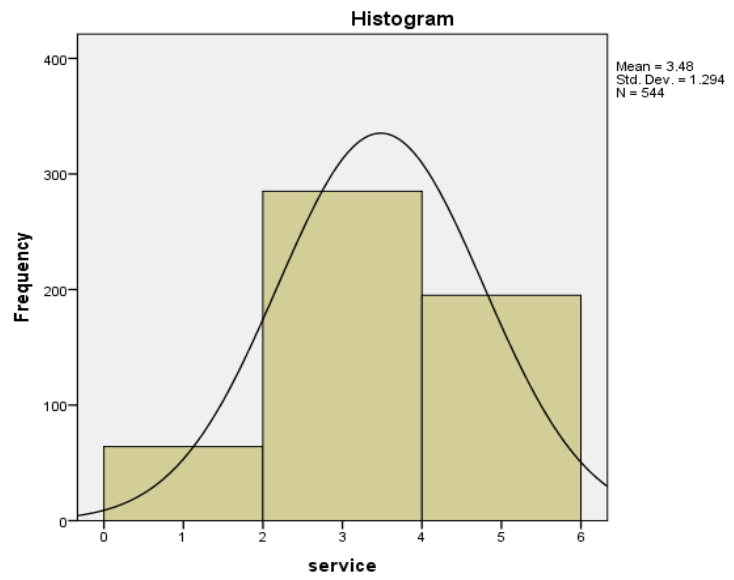

Gambar 9. Grafik Histogram Service

Gambar 9 merupakan grafik histogram variabel service dengan ratarata adalah 3,48. variabel service memiliki data normal. 
Tabel 8. Tabel Hasil

\begin{tabular}{|c|c|c|}
\hline variabel & Total & Skor \\
\hline \multicolumn{3}{|l|}{ Performance } \\
\hline Pernyataan 1 & 408 & $29,82 \%$ \\
\hline Pernyataan 2 & 474 & $34,65 \%$ \\
\hline Pernyataan 3 & 486 & $35,53 \%$ \\
\hline Rata-rata & 456 & \\
\hline \multicolumn{3}{|l|}{ Information } \\
\hline Pernyataan 4 & 508 & $18,50 \%$ \\
\hline Pernyataan 5 & 454 & $16,53 \%$ \\
\hline Pernyataan 6 & 464 & $16,90 \%$ \\
\hline Pernyataan 7 & 438 & $15,95 \%$ \\
\hline Pernyataan 8 & 452 & $16,46 \%$ \\
\hline Pernyataan 9 & 430 & $15,66 \%$ \\
\hline Rata-rata & 457,66 & \\
\hline \multicolumn{3}{|l|}{ Economy } \\
\hline Pernyataan 10 & 484 & $51,93 \%$ \\
\hline Pernyataan 11 & 448 & $48,07 \%$ \\
\hline Rata-rata & 466 & \\
\hline \multicolumn{3}{|l|}{ Control } \\
\hline Pernyataan 12 & 472 & $34,91 \%$ \\
\hline Pernyataan 13 & 452 & $33,43 \%$ \\
\hline Pernyataan 14 & 428 & $31,66 \%$ \\
\hline Rata-rata & 450,67 & \\
\hline \multicolumn{3}{|l|}{ Efficiency } \\
\hline Pernyataan 15 & 464 & $50,21 \%$ \\
\hline Pernyataan 16 & 460 & $49,79 \%$ \\
\hline Rata-rata & 462 & \\
\hline \multicolumn{3}{|l|}{ Service } \\
\hline Pernyataan 17 & 474 & $24,79 \%$ \\
\hline Pernyataan 18 & 448 & $23,43 \%$ \\
\hline Pernyataan 19 & 470 & $24,58 \%$ \\
\hline Pernyataan 20 & 520 & $27,20 \%$ \\
\hline Rata-rata & 478 & \\
\hline
\end{tabular}

Tabel 8 merupakan hasil dari pengolahan data berdasarkan responden yang telah didapat. Semua data yang diperoleh dapat digunakan dan memiliki nilai rata yang baik. Berdasarkan hasil tersebut ditemukan skor rata-rata untuk setiap variabel memiliki nilai cukup baik dengan skor terendah dimiliki oleh variabel control.

Berdasarkan hasil yang diperoleh pada penjelasan di atas maka dapat diberikan rekomendasi pengembangan berikutnya pada variabel control yang memiliki nilai terendah. Rekomendasi pengembangan berikutnya diarahkan pada perbaikan terhadap peringatan bahwa akun portal akademik sudah digunakan pada perangkat lain. Hal ini menunjang pada factor control pengguna portal terhadap akunnya. Serta dapat meningkatkan keamanan portal.

\section{KESIMPULAN}

Hasil dari penelitian terhadap portal akademik yang telah dilakukan terhadap kepuasan pengguna menggunakan variabel performance, information, economy, control, eficiency, dan service ditemukan hasil analisis deskriptif data pada variabel performance memiliki skor rata-rata 456, variabel information memiliki skor ratarata 457,66, variabel economy memiliki skor rata-rata sebanyak 466, variabel control memiliki skor rata-rata sebanyak 450,67, variabel eficiency menghasilkan skor rata-rata sebanyak 462, variabel service menghasilkan skor rata-rata sebanyak 478. Berdasarkan hasil skor ratarata yang telah diperoleh maka portal akademik memiliki tingkat kepuasan yang cukup baik bagi pengguna. Namun berdasarkan skor yang diperoleh variabel control dengan skor rata-rata terendah dapat menjadi prioritas pengembangan portal akademik ke depannya sehingga tingkat kepuasan pengguna dapat meningkat yang fokus pada peringatan terhadap penggunaan akun jika lebih dari 1 perangkat. Metode ini sangat membantu dalam melihat tingkat kepuasan pengguna terhadap portal akademik. Variabel yang digunakan jelas menunjukkan terhadap kebutuhan pengguna terhadap portal sebagai acuan pengembangan portal.

\section{DAFTAR PUSTAKA}

Agustina, Nani. "Evaluasi Pengggunaan Sistem Informasi ERP Dengan Metode Pieces Framework". Jurnal 
Informatika, Vol.5 No.2. September 2018, pp. 278-286.

Elmawati, Veni Wedyawati, Yulmi Sari. "Perancangan Sistem Informasi Data Rekam Medis Puskesmas Kumanis Kabupaten Sijunjung Dengan Menggunakan Bahasa Pemrograman Visual Basic.Net". Jurnal Sains dan Teknologi, Vol.20 No.1. Juni 2020, pp. 1-6.

Hamid, Abdul, et all. "Sistem Informasi Pendaftaran Uji Kompetensi Pada Lembaga Sertifikasi Profesi Pertanian Organik Jakarta". Jurnal Sains dan Teknologi, Vol.20 No.1. Juni 2020, pp. 12-19.

Indrawati, et all. "Analisis Tingkat Kepuasan Pengguna Sistem Informasi Perpustakaan Menggunakan Pieces Framework". Ilkom Jurnal Ilmiah, Vol. 11 No. 2. Agustus 2019. pp. 118128.

Jamaludin. "Pengaruh Curent Ratio dan Total Assets Turn Over Terhadap Struktur Modal pada PT. Unilever Indonesia, Tbk". Jurnal Ilmiah Manajemen Forkamma. Vol. 2, No.1 Maret 2019. pp. 31-53.

Nuryanti, Yulis. "Kajian Penerapan Sistem Informasi Akademik Dengan Menggunakan Metode Pieces Dalam Meningkatkan Kepuasan Civitas Akademika Stie-Stmik Insan Pembangunan". Jurnal IPSIKOM. Vol. 5. No. 2. Desember 2017. pp. 118.

Safarudin, Muhamad Sigid. "Analisis Kepuasan Pengguna Marketplace Tokopedia Dengan Metode PIECES di Tokopedia Community Batam". SNISTEK. 2018. pp. 109-114.

Sari, Yolanda Rizyta dan Evy Nurmiati. "Analisis Kepuasan Pengguna Google
Classroom Menggunakan PIECES Framework (Studi Kasus: Prodi Sistem Informasi UIN Jakarta)". Infotekjar. Vol. 5 No. 2. Maret 2021. pp. 77-82.

Zahra, R. Ratika dan Nofha Rina. "Pengaruh Celebrity Endorser Hamidah Rachmayanti Terhadap Keputusan Pembelian Produk Online Shop Mayoutfit Di Kota Bandung". Jurnal Lontar. Vol.6, No. 1. 2018. pp. 43-57. 